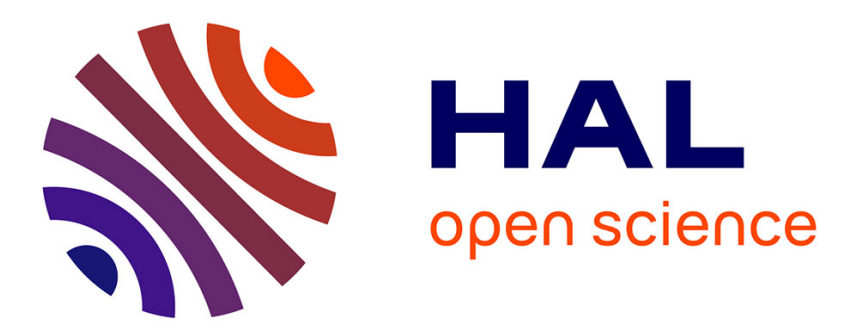

\title{
Skew of mantle upwelling beneath the East Pacific Rise governs segmentation
}

Douglas R. Toomey, David Jousselin, Robert A Dunn, William S D Wilcock, R. S Detrick

\section{- To cite this version:}

Douglas R. Toomey, David Jousselin, Robert A Dunn, William S D Wilcock, R. S Detrick. Skew of mantle upwelling beneath the East Pacific Rise governs segmentation. Nature, 2007, 446 (7134), pp.409-414. 10.1038/nature05679 . hal-02379523

\section{HAL Id: hal-02379523 \\ https://hal.univ-lorraine.fr/hal-02379523}

Submitted on 25 Nov 2019

HAL is a multi-disciplinary open access archive for the deposit and dissemination of scientific research documents, whether they are published or not. The documents may come from teaching and research institutions in France or abroad, or from public or private research centers.
L'archive ouverte pluridisciplinaire HAL, est destinée au dépôt et à la diffusion de documents scientifiques de niveau recherche, publiés ou non, émanant des établissements d'enseignement et de recherche français ou étrangers, des laboratoires publics ou privés. 


\section{Skew of Mantle Upwelling Beneath the East Pacific Rise Governs Segmentation}

Douglas R. Toomey*, David Jousselin ${ }^{\dagger}$, Robert A. Dunn ${ }^{\star}$, William S. D. Wilcock ${ }^{\S} \&$ R. S. Detrick $^{¥}$

*Department of Geological Sciences, University of Oregon, Eugene, Oregon 97403, USA

${ }^{\dagger}$ Université de Nancy CRPG, BP 20, 54501 Vandoeuvre-Les-Nancy Cedex, France

${ }^{\ddagger}$ Department of Geology and Geophysics, University of Hawaii-SOEST, Honolulu, Hawaii, USA

${ }^{\S}$ School of Oceanography, University of Washington, Seattle, Washington 98195, USA

${ }^{¥}$ Department of Geology and Geophysics, Woods Hole Oceanographic Institution, Woods Hole, Massachusetts 02543, USA

Mantle upwelling is essential to spreading centre processes, yet there are few constraints on its detailed structure beneath active ridges. Here we use seismic imaging of the East Pacific Rise to show that the isotropic and anisotropic structure of the mantle is rotated beneath the plate boundary. The isotropic structure defines the pattern of magma delivery from the mantle to the crust. We find that between transforms, the tectonic and magmatic segmentation of the rise correlates well with the distribution of mantle melt. The anisotropic structure defines the direction of mantle flow. Mantle flow is rotated nearly $10^{\circ}$ anticlockwise of the plate-spreading direction and thus contributes to the transpressive and transtensional tectonics of nearby transforms. We conclude that skew of asthenospheric upwelling and 
transport governs segmentation of the East Pacific Rise and variations in the intensity of ridge crest processes.

The origin of tectonic and magmatic segmentation of oceanic spreading centres is controversial. By one view, along-axis differences in ridge crest processes result directly from three-dimensional mantle upwelling ${ }^{1-4}$. Sites of vigorous volcanic and hydrothermal activity are thus thought to overly regions of greater magma supply. Poor knowledge of mantle structure, however, has given rise to diverging opinions on the scale of threedimensional upwellings ${ }^{2-6}$. Alternatively, segmentation of ridge crest processes may be regulated by the tectonic rifting of young lithosphere ${ }^{7}$, and thus not directly linked to the form of mantle upwelling. In this case mantle flow could be either two-dimensional ${ }^{8}$ or three-dimensional mantle upwellings may be less influential owing to efficient along-axis transport of magma, either by viscous flow or diking at crustal depths ${ }^{9}$.

Along the global ridge system, the fast-spreading East Pacific Rise (EPR) between the Siqueiros and Clipperton transforms (Fig. 1) currently offers our best opportunity for revealing the role of the mantle in governing ridge crest processes. There are several reasons for this. This section of the EPR encompasses a full spectrum of rise axis discontinuities, including: two large-offset transforms; large, long-lived $\left(9^{\circ} 03^{\prime} \mathrm{N}\right)$ and small, short-lived $\left(9^{\circ} 37^{\prime} \mathrm{N}\right)$ overlapping spreading centres (OSCs) ${ }^{10-12}$; and smaller scale morphologic ${ }^{3}$, petrologic $c^{5,12}$ and seismic ${ }^{6,13,14}$ discontinuities that are typical of fastspreading ridge segments. Accompanying these axial discontinuities are well known alongaxis variations in seafloor depth, axial high morphology ${ }^{15}$, crustal structure and thickness ${ }^{16-}$ ${ }^{19}$, lava chemistry ${ }^{5,12,20,21}$, and seafloor hydrothermal ${ }^{22,23}$ and biologic activity ${ }^{22}$. These characteristics of the EPR, including the origin of ridge crest segmentation, have been hypothesized to result from the supply of magma from the mantle. 
The UNDERSHOOT experiment was conducted to seismically image the crustal and mantle structure between the Clipperton and Siqueiros transforms in order to determine the pattern of magma delivery from the mantle to the crust. Here we present the first images of mantle structure beneath an entire ridge segment bounded by long-lived tectonic discontinuities (Fig. 1). Good image resolution allows direct comparison among the scales of tectonic and magmatic segmentation observed along this section of the EPR with the physical structure of the topmost mantle. Our results allow conclusions to be drawn about the driving and controlling processes for segmentation of fast-spreading ridges.

\section{Experiment Geometry and Tomographic Imaging}

The distribution of seismic receivers and sources used to image crustal and mantle structure is shown in Fig. 1. The experiment constrains the structure of the uppermost mantle within $4 \mathrm{~km}$ of the Moho and within an area extending $15 \mathrm{~km}$ to either side of the rise axis and 230 $\mathrm{km}$ along the spreading centre. A three-dimensional model of off-axis crustal structure and thickness is used to analyse the mantle refraction data (see Supplementary Information).

The $P n$ data provide good spatial sampling of mantle structure throughout the image volume (Fig 2a). Pn travel time residuals plotted by azimuth reveal a $\cos (2 \Theta)$ pattern (Fig. b), a signal indicative of azimuthal seismic anisotropy. The azimuth of anisotropy (i.e., the fast direction for $P n$ propagation) is $\mathrm{N} 73^{\circ} \mathrm{E} \pm 1^{\circ}$ (see Supplementary Information). Tomographic inversions, discussed below, confirm this result. The azimuth of anisotropy is

rotated $9^{\circ}$ anticlockwise with respect to the predicted spreading direction ${ }^{24}\left(\mathrm{~N} 82^{\circ} \mathrm{E}\right)$. Plotted by rise crossing point, $P n$ travel time residuals show evidence for anomalously low and variable upper mantle velocities (Fig. 2c). The average isotropic velocity that best fits the $P n$ data $(7.6 \mathrm{~km} / \mathrm{s})$ is less than typical upper mantle velocities, whereas delays are greater 
toward the centre of the transform-bounded segment and less within $20 \mathrm{~km}$ of the transforms.

Tomographic inversion (see Supplementary Information) of $P n$ travel time data reveals a mantle low-velocity zone (MLVZ) that is segmented on a scale comparable to tectonic offsets of the EPR (Fig 1). The MLVZ decreases in amplitude toward each transform, in agreement with the decrease in mean Pn delays (Fig. 2c). Between transforms, the MLVZ follows two en echelon trends that are orthogonal to the azimuth of seismic anisotropy (Fig. 1b, green lines). The en echelon trends are offset in a right lateral sense and rotated anticlockwise with respect to the axis of plate spreading. Due to this rotation, much of the MLVZ is not centred beneath the axial neovolcanic zone. Beneath and immediately north of the OSC the MLVZ steps rightward, defining a geometrically complex transitional region that connects the en echelon trends of the MLVZ. The transitional region, located between $9^{\circ} 00^{\prime} \mathrm{N}$ and $9^{\circ} 18^{\prime} \mathrm{N}$, is shifted northward of the OSC itself and coincides with a region of thicker crust $^{18,19}$.

North of the OSC, local minima of the MLVZ occur at intervals of approximately 25 km. Pronounced sub-axial anomalies are located near $9^{\circ} 56^{\prime} \mathrm{N}$ and $9^{\circ} 44^{\prime} \mathrm{N}$. Equally pronounced anomalies are centred more than $10 \mathrm{~km}$ off-axis at $9^{\circ} 32^{\prime} \mathrm{N}$ and a few kilometres off-axis at $9^{\circ} 15^{\prime} \mathrm{N}$. Between $9^{\circ} 15^{\prime} \mathrm{N}$ to $9^{\circ} 35^{\prime} \mathrm{N}$ the MLVZ is located 5 to $15 \mathrm{~km}$ east of the neovolcanic zone. In the same region, magnetotelluric studies detect anomalously low mantle conductivities 10 to $20 \mathrm{~km}$ east of the rise axis ${ }^{25}$. South of the OSC there is a local minima of the MLVZ near $8^{\circ} 43^{\prime} \mathrm{N}$. Within our study area, the most pronounced mantle anomaly occurs beneath the eastern limb of the OSC where several compliance measurements detect near-Moho sills ${ }^{26}$. The transition of the MLVZ between opposing 
limbs of the OSC coincides well with a similar transition of the crustal-level axial magma chamber reflector $^{27}$ (Fig 1).

We conducted a series of tomographic inversions for fixed models of mantle anisotropy to explore the tradeoffs between isotropic and anisotropic structure. An isotropic mantle results in a large chi-squared travel time misfit $(\sim 6)$. Fig. 3 shows that the data misfit is smallest when the azimuth of anisotropy imposed on the tomographic procedure is identical to that estimated from the raw $P n$ data (Fig. 2b). The data misfit is significantly larger when azimuthal anisotropy matches the predicted spreading direction. A robust result of our analysis is that both the azimuth of seismic anisotropy relative to the spreading direction and the axis of the MLVZ with respect to the plate boundary are rotated anticlockwise by similar amounts.

The Supplementary Information summarizes our analysis of model sensitivity and resolution and details how our current results differ from previously published studies. Therein we show that a ray-tracing error in a previous study of the $9^{\circ} 03^{\prime} \mathrm{N} \mathrm{OSC}^{28}$ resulted in an incorrect image.

\section{Skew of Mantle Upwelling and Asthenospheric Flow}

The isotropic component of our tomographic image constrains the distribution of melt in the top few kilometres of the mantle. Regions of anomalously low seismic velocities are consistent with higher melt fractions. If melt resides in film-like geometries ${ }^{29,30}$, then our results can be explained by the presence of 1-3\% melt (see Supplementary Information); melt fractions would be greater if distributed anisotropically or if melt pockets are more spherically shaped. We attribute the MLVZ to a region of melt accumulation that lies beneath the base of newly formed oceanic crust and that overlies the melt production region 
located at depths of several tens of kilometres. By this view, the axis of mantle upwelling that gives rise to decompression melting is skewed with respect to the plate boundary.

The anisotropic component of our model constrains the direction of shallow mantle flow. This is because the maximum compressional wave speed for single crystal olivine parallels the crystallographic a-axis and deformation of mantle peridotites preferentially aligns the a-axis in the flow direction ${ }^{31}$. We conclude that the direction of shallow mantle flow is skewed by $9^{\circ}$ with respect to the plate-spreading direction. The transport of asthenosphere away from the EPR and the axis of decompression upwelling are thus rotated anticlockwise in a coherent manner (Fig. 1).

The rotation of mantle flow beneath the EPR is in the same direction as recent changes in the Euler pole for Pacific-Cocos plate motion, which has been progressing anticlockwise for the past several million years ${ }^{32}$. Ongoing changes in plate kinematics ${ }^{32}$, however, are lagging behind the current direction of asthenospheric flow. We propose that the skew of mantle flow beneath the EPR is one of the driving forces for changes in plate boundary kinematics. Specifically, basal tractions imposed by mantle flow are contributing to anticlockwise changes in the spreading direction and the transpressional and transtensional tectonics of the Clipperton and Siqueiros transforms ${ }^{32}$, respectively (Fig. 4). The lag of the rigid plate system relative to the viscous asthenosphere indicates that transpressive transforms, such as the Clipperton, limit the rate at which plates adjust to changes in plate driving forces ${ }^{33}$.

\section{Relation of Ridge Crest Segmentation to Mantle Structure}

Our study shows that the tectonic segmentation of the EPR correlates well with the pattern of melt delivery from the mantle to the crust. Near transforms or first-order offsets of the 
ridge crest $^{3}$, the increase in seismic velocities is consistent with a decrease in the amount of melt at near Moho depths and possibly a decrease in temperature. Toward the Siqueiros transform the increase in seismic velocity is most pronounced, consistent with the observed decrease in crustal thickness ${ }^{19}$.

Between transform offsets, the EPR is structurally segmented by OSCs or secondorder ridge crest discontinuities ${ }^{3}$. The right-stepping $9^{\circ} 03^{\prime} \mathrm{N}$ OSC occurs near the ends of en echelon segments of the MLVZ, or where the axis of mantle upwelling is sheared in a right-lateral sense. We suggest that the large-scale rotation of mantle upwelling, with respect to the current Euler pole of Pacific-Cocos plate motion, governs the formation and evolution of the OSC (Fig. 4). In this view, mantle upwellings organize into en echelon segments and large-offset OSCs provide an accommodation zone that transitions the lithospheric plate boundary from one segment of mantle upwelling to another. A previous hypothesis for the origin of OSCs attributes them to variations in the duration, timing or intensity of magmatic pulses that inflate crustal magma chambers and that propagate along the plate boundary, in which case a reduced magma supply is expected near second-order discontinuities ${ }^{4}$. An alternative model infers that OSCs are entirely lithospheric features that form in response to changes in plate motion ${ }^{7}$. We conclude that the segmentation of the EPR by OSCs is a direct result of en echelon upwelling at mantle depths. However, OSCs do not occur near regions of reduced magma supply nor is their evolution related to along-axis migration of magmatic pulses away from centres of replenishment toward magma-starved discontinuities. We propose that OSCs form because the geometry of the rigid plate system is inconsistent with the underlying orientation and geometry of asthenospheric upwelling. As the pattern of mantle upwelling evolves, OSCs will respond to maintain their positions where the axis of upwelling is sheared in the cross-axis direction. We predict that both the size and the sense of offset of an OSC, as well as its 
propagation history, will be related to the underlying and evolving pattern of mantle upwelling.

Between transforms and OSCs the EPR is subtly segmented at a scale of $\sim 25 \mathrm{~km}$, referred to as third-order or volcanic segmentation ${ }^{3,34}$. Multidisciplinary studies reveal that volcanic segments are chemically, structurally and geologically distinct. Petrologic data show that lavas erupted within volcanic segments are compositionally similar, yet differences in lava chemistry between volcanic segments can be pronounced ${ }^{5,12}$. Geophysical studies indicate that the centres of volcanic segments are associated with a more pronounced magmatic system at mid- to lower-crustal depths, and elevated temperatures within a thermal boundary layer that connects the magmatic and hydrothermal systems ${ }^{6,14,35}$. Near the boundaries of volcanic segments, seismic reflection and tomographic imaging detect abrupt changes in mid- to upper-crustal structure ${ }^{6,13,14,35,36}$. Lastly, seafloor mapping shows that volcanic and tectonic features are also segmented at this scale ${ }^{34}$. The structure of the MLVZ correlates well with previous indicators of thirdorder segmentation, supporting the hypothesis that volcanic segmentation of the EPR is inherited from variations in mantle melt delivery ${ }^{5,6,37}$. We note that the spacing of volcanic segments is similar to that of diapirs mapped in the Oman ophiolite ${ }^{38,39}$. Additional studies will be necessary to determine if this is a coincidence or the result of dynamic upwelling.

\section{Relation of the Intensity of Ridge Crest Activity to Skew of Mantle Upwelling}

We find that the state of volcanic and tectonic activity along the ridge correlates with the cross-axis distance to a centre of mantle melt delivery. Above rise-centred delivery of mantle melt (e.g., $\left.9^{\circ} 50^{\prime} \mathrm{N}\right)$, lavas are young and fissure density is decreased ${ }^{22,40,41}$. Where mantle melt arrives off axis (e.g., $\left.9^{\circ} 30^{\prime} \mathrm{N}\right)$, older lavas and increased fissuring characterize 
the axial high. Within our study area, the oldest lavas and the highest density of fissured seafloor $^{22,41}$ is found where the MLVZ is farthest from the rise $\left(9^{\circ} 20^{\prime} \mathrm{N}\right)$. Axial eruptive styles also differ, with larger volume, longer duration flows inferred where off-axis delivery of mantle melt occurs ${ }^{42}$. These relations suggest that shorter repose times and smaller eruption volumes may typify volcanoes fed by rise-centred delivery of mantle melt.

The vigour of hydrothermal venting also correlates with the pattern of magma delivery. In regions of rise-centred delivery, high-temperature hydrothermal venting is associated with recent volcanism and vent-supported biologic communities are abundant $^{22,40,41}$. Either more mature or non-existent high-temperature venting and a general decrease in the abundance of vent-supported biota ${ }^{22,40,41}$ is observed where mantle melt arrives off axis. A transition from on- to off-axis delivery of mantle melt occurs near $9^{\circ} 37^{\prime} \mathrm{N}$, where a ridge discontinuity separates a volcanic section of the axial high from a tectonic one and demarcates a significant hydrothermal boundary ${ }^{12}$. North of $9^{\circ} 37^{\prime} \mathrm{N}$, lavas are less evolved (higher $\mathrm{MgO}$ content), eruption temperatures are $>1190^{\circ} \mathrm{C}$, hydrothermal venting is commonly $>350^{\circ} \mathrm{C}$ and vent fluids are consistent with derivation from the vapour phase of phase-separated fluids ${ }^{12,23}$. In contrast, south of $9^{\circ} 37^{\prime} \mathrm{N}$ where mantle melt is delivered off axis, basalts are more evolved (lower $\mathrm{MgO}$ ), eruption temperatures are $<1190^{\circ} \mathrm{C}$, hydrothermal venting temperatures are $<325^{\circ} \mathrm{C}$ and vent fluids are derived from the brine phase of phase-separated fluids ${ }^{12,23}$.

\section{Magma Plumbing and the Segmentation of the EPR}

Three significant new findings of our study are that: (i) mantle upwelling and asthenospheric flow are skewed beneath the plate boundary, thus the delivery of mantle melt is frequently not centred beneath the rise; (ii) the $9^{\circ} 03^{\prime} \mathrm{N}$ OSC, a second-order discontinuity of the EPR, occurs where en echelon segments of mantle upwelling are offset 
in the cross-axis direction, and (iii) between first- and second-order discontinuities the cross-axis offset between a centre of mantle melt delivery and the neovolcanic zone correlates with the intensity of rise crest volcanic, hydrothermal, and tectonic activity. Building on these results we propose a new model of magmatic segmentation beneath fastspreading ridges, illustrated in Fig. 4. In our model the skew of mantle upwelling beneath the plate boundary governs second-order segmentation of the EPR and the intensity of geologic processes occurring within third-order or volcanic segments. Above we discussed the implications of our results for transforms and OSCs.

Away from OSCs and transforms, volcanic segments receive mantle-derived melt from more-or-less equally spaced centres. In contrast to previous hypotheses, rise-parallel variations in ridge processes are not simply a function of magma supply or the along-axis redistribution of magma away from a mantle source ${ }^{3,4,9}$. Instead, the cross-axis offset between a centre of mantle melt delivery and the associated axial volcano causes axisparallel changes in ridge crest processes. We illustrate our magma-plumbing model with two cross-sections (Fig 4). One is through a rise-centred site of mantle melt delivery and a volcano characterized by frequent extrusive volcanism and vigorous seafloor hydrothermal and biologic systems; this is representative of the rise near $9^{\circ} 50^{\prime} \mathrm{N}^{22,40}$ (Figs. 1 and 4). By contrast, the second cross-section is through an off-axis centre of melt delivery that feeds melt to an axial volcano where seafloor eruptions occur less frequently, surface tectonic extension is greater and seafloor hydrothermal and biologic activity are less intense; this is representative of the rise near $9^{\circ} 30^{\prime} \mathrm{N}^{22,40,41}$. The contrasting processes at these two sites cannot be attributed to differences in the size and shape of upper crustal magma chambers, which are similar ${ }^{13}$. Nor is it likely that the observed differences in hydrothermal activity can be attributed to near surface permeability, which is expected to be greater where seafloor fissuring and faulting is greater ${ }^{41}$. We further rule out magma supply as the 
controlling factor since crustal thickness, and by association the long-term magma supply, is similar at each location ${ }^{18,19}$. We propose that as the cross-axis offset between a centre of mantle melt delivery and the rise crest increases so does the differentiation of magma that is delivered to the volcano. Magmatic differentiation decreases magma temperature, changes its composition, increases its density and enhances the exsolution of magmatic volatiles. We infer that such fundamental changes in the qualities of magma will shape near-surface processes driven by crustal magma chambers.

Our model predicts that magma entering the crustal system from a rise-centred site of mantle melt delivery will have undergone relatively less differentiation. Such magma will be higher in temperature, more buoyant (i.e., higher $\mathrm{MgO}$ ) and retain a fuller complement of volatiles, thus increasing the breeching of the reaction zone above the axial magma chamber, the exchange of energy between the magmatic and hydrothermal systems and the recurrence of extrusive volcanism that localizes vigorous, high-temperature venting and biologic activity. Sites of rise-centred delivery of mantle melt are most likely to be characterized as volcanically and hydrothermally robust on the basis of surface geology. In the case of off-axis delivery of mantle melt our model predicts that lateral migration of melt at sub-crustal depths will increase igneous differentiation. Crustal magma reservoirs will thus receive melt that is both cooler and denser (lower $\mathrm{MgO}$ ) relative to reservoirs above rise-centred upwellings. Depending on the degree of differentiation, considerable open system fractionation of magmatic volatiles could occur off axis, in which case the pressurization of a ridge crest magma chamber by volatiles would be less. A decrease in the volatile content of an axial magma chamber should decrease the breeching of the hydrothermal reaction zone and reduce the frequency of volcanic eruptions. In this setting, localized high-temperature hydrothermal venting may be intermittent and lowertemperature, diffuse-flow venting could prevail. Such characteristics are commonly 
attributed to magma starvation. In our magma plumbing model two axial volcanoes, or third-order segments, can receive similar volumes of magma, but behave differently (extrusive versus intrusive) because of differentiation-induced changes in magma quality.

Previous models of mid-ocean ridges have commonly assumed that magma supply controls segmentation, that asthenospheric transport parallels the spreading direction and that mantle upwelling and melt delivery is symmetric about the rise axis. Ours is the first study to show large-scale skew of mantle upwelling beneath mid-ocean ridges and as such it renews the debate over the origin and significance of spreading centre segmentation. One implication of our results is that local plate motions alone are not the sole cause of subridge mantle flow. On the contrary, the skew of mantle upwelling and transport can act as a driving force for the tectonic reorganization of the EPR and cause along-axis variations in the intensity of ridge crest processes. We speculate that the skew of the sub-ridge asthenosphere owes its origin to global patterns of mantle flow, which are dominantly controlled by the viscous coupling between subducting oceanic slabs and the surrounding mantle. If this speculation holds, it implies that the flux of slabs into the mantle may be linked to the segmentation of mid-ocean ridges.

Received XX YYY

\section{Supplementary Information}

\section{Acknowledgments}


Fig. 1. a, Location and geometry of the seismic experiment and b, tomographic image of the mantle low-velocity zone (MLVZ) and orientation of mantle anisotropy. a, The Clipperton and the Siqueiros transforms bound the study area. Dashed lines shows the location of the plate boundary. Seismic data were collected on 37 ocean bottom receivers from the Woods Hole Oceanographic Institution (white symbols). Twenty of these were Office of Naval Research, three-component seismometers (OBSs) equipped with $1-\mathrm{Hz}$ geophones and a hydrophone; the remaining units were ocean bottom hydrophones $(\mathrm{OBHs})$. The seismic source was the R/V Ewing's 20-gun, 8500-cubic-inch (139 litre) air gun array, fired at intervals of $210 \mathrm{~s}$ (shot spacing of $500 \mathrm{~m}$ ) along the tracks indicated by solid black lines. Locations of axial magma chamber reflector from multichannel seismics (MCS) shown in red ${ }^{13,16,27}$. Black box indicates location of 3-D MCS experiment. b, Tomographic image of mantle P-wave velocity; contour interval is $0.1 \mathrm{~km} / \mathrm{s}$. Green lines with arrowheads indicates azimuth of seismic anisotropy (see Figs. $2 b$ and 3 ); black lines with arrowheads indicate plate-spreading direction ${ }^{24}$. Green lines without arrowheads are perpendicular to seismic anisotropy and indicate locations of en echelon segments of MLVZ. Seafloor compliance measurements indicated by white symbols ${ }^{26}$; larger white squares are locations where near-Moho melt sills were detected.

Fig. 2. a, Map of the distribution of the $4892 \mathrm{Pn}$ ray paths used to image mantle structure. Pn data sample the mantle within about $\pm 15 \mathrm{~km}$ of the rise axis. $\mathbf{b}$, Mean $P n$ delay plotted by azimuth. Delays are calculated relative to an isotropic model, corrected to $40 \mathrm{~km}$ range and binned at intervals of $5^{\circ}$. Vertical bars indicate uncertainty in mean delay as determined by a student t-test $(95 \%$ confidence interval). Solid line is the best-fit $\cos (2 \Theta)$ curve. The azimuth of 
seismic anisotropy is $\mathrm{N} 73^{\circ} \mathrm{E} \pm 1^{\circ}$. c, Mean $P n$ delay plotted by rise crossing point. Delays are calculated relative to $7.8 \mathrm{~km} / \mathrm{s}$ and have been corrected for seismic anisotropy ( $6 \%$ with fast axis azimuth of $\left.\mathrm{N} 73^{\circ} \mathrm{E}\right)$. Data are binned at intervals of 10 $\mathrm{km}$ and bars indicate uncertainty in mean delay time as determined from a student t-test (95\% confidence interval).

Fig. 3. Data misfit following tomographic inversion versus azimuth of seismic anisotropy imposed on starting model. For each inversion, percentage $(6 \%)$ and azimuth of anisotropy are held fixed. Data misfit is a minimum for an azimuth of $\mathrm{N} 73^{\circ} \mathrm{E}$. Misfit is significantly larger when azimuth of anisotropy parallels the NUVEL-1A spreading direction ${ }^{24}$.

Fig. 4. Proposed model of magmatic segmentation beneath the East Pacific Rise. a, Map view showing plate boundary and tectonic discontinuities (solid black lines), regions of melt accumulation beneath the crust (orange area labelled mush), orientation of mantle flow (green lines with arrowheads) and trend of en echelon segments of the melt accumulation regions (green lines without arrowheads; perpendicular to mantle flow). Thin black line with arrowheads indicates NUVEL$1 \mathrm{~A}$ spreading direction ${ }^{24}$. Large, paired arrows indicate regions of transpression (solid) and transtension along the Clipperton and Siqueiros transforms, respectively ${ }^{32}$. Circles with roman numerals indicate location of cross-sections shown to right. b. Two rise-perpendicular sections depicting magma plumbing beneath rise-centred (top) and off-axis (bottom) sites of mantle melt delivery. Above centres of melt delivery magma accumulates at near-Moho depths, presumably within a mush-like compaction layer (orange region). Melt migration paths indicated by red arrows; near Moho melt sills indicated by red ellipses. Small 
grey circles depict the exsolution of magmatic volatiles that occurs during differentiation. Sites of rise-centred melt delivery are more likely to be hydrothermally active and resurfaced frequently by extrusive volcanism (plume and smooth seafloor in top section). Sites of off-axis delivery of mantle melt sustain greater amounts of tectonic extension, erupt less frequently and host more intermittent high-temperature hydrothermal activity (rougher seafloor in bottom section). 
1. Whitehead, J. A., Jr., Dick, H. J. B. \& Schouten, H. A mechanism for magmatic accretion under spreading centres. Nature 312, 146-148 (1984).

2. Schouten, H., Klitgord, K. D. \& Whitehead, J. A. Segmentation of mid-ocean ridges. Nature 317, 225-229 (1985).

3. Macdonald, K. C. et al. A new view of the mid-ocean ridge from the behaviour of ridge-axis discontinuities. Nature 335, 217-225 (1988).

4. Macdonald, K. C., Scheirer, D. S. \& Carbotte, S. M. Mid-ocean ridges: Discontinuities, segments and giant cracks. Science 253, 986-994 (1991).

5. Langmuir, C. H., Bender, J. F. \& Batiza, R. Petrological and tectonic segmentation

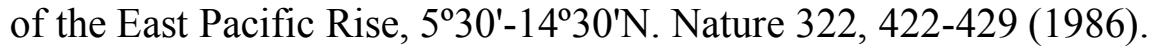

6. Toomey, D. R., Purdy, G. M., Solomon, S. C. \& Wilcock, W. S. D. The threedimensional seismic velocity structure of the East Pacific Rise near latitude $9^{\circ} 30^{\prime} \mathrm{N}$. Nature 347, 639-645 (1990).

7. Lonsdale, P. Segmentation of the Pacific-Nazca Spreading Center, $1^{\circ} \mathrm{N}-20^{\circ}$ S. J. Geophys. Res. 94, 12197-12226 (1989).

8. Parmentier, E. M. \& Morgan, J. P. Spreading rate dependence of three-dimensional structure in oceanic spreading centers. Nature 348, 325-328 (1990).

9. Bell, R. E. \& Buck, W. R. Crustal control of ridge segmentation inferred from observations of the Reykjanes Ridge. Nature 357, 583-586 (1992).

10. Sempéré, J.-C. \& Macdonald, K. C. Deep-tow studies of the overlapping spreading centers at $9^{\circ} 03^{\prime} \mathrm{N}$ on the East Pacific Rise. 5, 881-900 (1986).

11. Carbotte, S. M. \& Macdonald, K. C. East Pacific Rise $8^{0}-10^{0} 30^{\prime}$ N: Evolution of ridge segments and discontinuities from SeaMARC II and three-dimensional magnetic studies. J. Geophys. Res. 97, 6959-6982 (1992).

12. Smith, M. C. et al. Magmatic processes and segmentation at a fast spreading midocean ridge; Detailed investigation of an axial discontinuity on the East Pacific Rise crest at 9³7'N. Geochem. Geophys. Geosys. 2, doi:2000GC000134 (2001).

13. Kent, G. M., Harding, A. J. \& Orcutt, J. A. Distribution of magma beneath the East Pacific Rise between the Clipperton Transform and the $9^{\circ} 17^{\prime} \mathrm{N}$ Deval from forward modeling of common depth point data. J. Geophys. Res. 98, 13945-13969 (1993).

14. Dunn, R. A., Toomey, D. R. \& Solomon, S. C. Three-dimensional seismic structure and physical properties of the crust and shallow mantle beneath the East Pacific Rise at $9^{\circ} 30^{\prime}$ N. J. Geophys. Res. 105, 23537-23555 (2000).

15. Scheirer, D. S. \& Macdonald, K. C. Variation in cross-sectional area of the axial ridge along the East Pacific Rise: Evidence for the magmatic budget of a fast spreading center. J. Geophys. Res. 98, $7871-7885$ (1993).

16. Detrick, R. S. et al. Multi-channel seismic imaging of a crustal magma chamber along the East Pacific Rise. Nature 326, 35-41 (1987).

17. Vera, E. E. et al. The structure of 0- to 0.2-m.y.-old oceanic crust at $9^{\circ} \mathrm{N}$ on the East Pacific Rise from expanded spread profiles. J. Geophys. Res. 95, 15529-15556 (1990).

18. Barth, G. A. \& Mutter, J. C. Variability in oceanic crustal thickness and structure: Multichannel seismic reflection results from the northern East Pacific Rise. J. Geophys. Res. 101, 17951-17975 (1996). 
19. Canales, J. P., Detrick, R. S., Toomey, D. R. \& Wilcock, W. S. D. Segment-scale variations in the crustal structure of 150-300 kyr old fast spreading oceanic crust (East Pacific Rise, 8 degrees $15^{\prime} \mathrm{N}-10$ degrees $5^{\prime} \mathrm{N}$ ) from wide-angle seismic refraction profiles. Geophysical Journal International 152, 766-794 (2003).

20. Batiza, R. \& Niu, Y. Petrology and magma chamber processes at the East Pacific Rise $\sim 9^{\circ} 30^{\prime}$ N. J. Geophys. Res. 97, 6779-6797 (1992).

21. Perfit, M. R. et al. Small-scale spatial and temporal variations in mid-ocean ridge crest magmatic processes. Geology 22, 375-279 (1994).

22. Haymon, R. M. et al. Hydrothermal vent distribution along the East Pacific Rise crest $\left(9^{\circ} 09^{\prime}-54^{\prime} \mathrm{N}\right)$ and its relationship to magmatic and tectonic processes on fastspreading mid-ocean ridges. Earth Planet. Sci. Lett. 102, 513-534 (1991).

23. Von Damm, K. L. Chemistry of hydrothermal vent fluids from $9^{\circ}-10^{\circ}$, East Pacific Rise: "Time zero," the intermediate posteruptive period. J. Geophys. Res. 105, 11203-11222 (2000).

24. Gripp, A. E. \& Gordan, R. G. Young tracks of hotspots and current plate velocities. Geophy. J. Int. 150, 321-361 (2002).

25. Key, K. W. \& Constable, S. C. in Eos Trans., AGU, 84(46), Fall Meet. Suppl., Abstract B12A-0740 (2003).

26. Crawford, W. C. \& Webb, S. C. Variations in the distribution of magma in the lower crust and at the Moho beneath a the East Pacific Rise at $9^{\circ}-10^{\circ} \mathrm{N}$. Earth Planet Sci. Lett. 203, 117-130 (2002).

27. Kent, G. M. et al. Evidence from three-dimensional seismic reflectivity images for enhanced melt supply beneath mid-ocean-ridge discontinuities. Nature 406, 614-618 (2000).

28. Dunn, R. A., Toomey, D. R., Detrick, R. S. \& Wilcock, W. S. D. Continuous mantle melt supply beneath an overlapping spreading center on the East Pacific Rise. Science 291, 1955-1958 (2001).

29. Faul, U. H., Toomey, D. R. \& Waff, H. S. Intergranular basaltic melt is distributed in thin, elongated inclusions. Geophys. Res. Lett. 21, 29-32 (1994).

30. Hammond, W. C. \& Humphreys, E. D. Upper mantle seismic wave velocity; effects of realistic partial melt geometries. J. Geophys. Res. 105, 10975-10986 (2000).

31. Nicolas, A. \& Christensen, N. I. in Composition, Structure, and Dynamics of the Lithosphere-Asthenosphere System (eds. Fuchs, K. \& Froidevaux, C.) 111-123 (American Geophys. Union, Washington D.C., 1987).

32. Pockalny, R. A., Fox, P. J., Fornari, D. J., Macdonald, K. C. \& Perfit, M. R. Tectonic Reconstructio of the Clipperton and Siqueiros Fracture Zones: Evidence and consequences of plate motion change for the last 3 Myr. J. Geophys. Res. 102, 3167-3181 (1997).

33. Richards, M. A. \& Lithgow-Bertelloni, C. Plate motion changes, the HawaiianEmperor bend, and the apparent success and failure of geodynamic models. Earth Plan. Sci. Lett. 137, 19-27 (1996).

34. White, S. M., Haymon, R. M., Fornari, D. J., Perfit, M. R. \& Macdonald, K. C. Correlation between volcanic and tectonic segmentation of fast-spreading ridges: 
Evidence from volcanic structures and lava flow morphology on the East Pacific Rise at $9^{\circ}-10^{\circ}$ N. J. Geophys. Res. 107, 10.1029/2001JB000571 (2002).

35. Toomey, D. R., Solomon, S. C. \& Purdy, G. M. Tomographic imaging of the shallow crustal structure of the East Pacific Rise at 9॰30'N. J. Geophys. Res. 99, 24,135-24,157 (1994).

36. Tian, T., Wilcock, W. S. D., Toomey, D. R. \& Detrick, R. S. Seismic heterogeneity in the upper crust near the 1991 eruption site on the East Pacific Rise. Geophys. Res. Lett 27, 2369-2372 (2000).

37. Dunn, R. A. \& Toomey, D. R. Seismological evidence for three-dimensional melt migration beneath the East Pacific Rise. Nature 388, 259-262 (1997).

38. Nicolas, A. Structures of ophiolites and dynamics of oceanic lithosphere (ed. Nicolas, A.) (Kluwer Acad. Pub., Dordrecht, 1989).

39. Jousselin, D., Nicolas, A. \& Boudier, F. Detailed mapping of a mantle diapir below a paleo-spreading center in the Oman ophiolite. J. Geophys. Res. 103, 18,15318,170 (1998).

40. Fornari, D. J., Haymon, R. M., Perfit, M. R., Gregg, T. K. P. \& Edwards, M. H. Axial summit trough of the East Pacific Rise $9^{\circ}-10^{\circ} \mathrm{N}$ : Geological constraints and evolution of the axial zone of fast spreading mid-ocean ridges. J. Geophys. Res. 103, 9827-9855 (1998).

41. Wright, D. J., Haymon, R. M. \& Fornari, D. J. Crustal fissuring and its relationship to magmatic and hydrothermal processes on the East Pacific Rise crest $\left(9^{\circ} 12^{\prime}\right.$ to 54'N). J. Geophys. Res. 100, 6097-6120 (1995).

42. Soule, S. A. et al. Channelized lava flows at the East Pacific Rise crest $9^{\circ}-10^{\circ} \mathrm{N}$ : The importance of off-axis lava transport in developing the architecture of young oceanic crust. Geochem. Geophys. Geosys. 6, doi:10.1029/2005GC000912 (2005). 


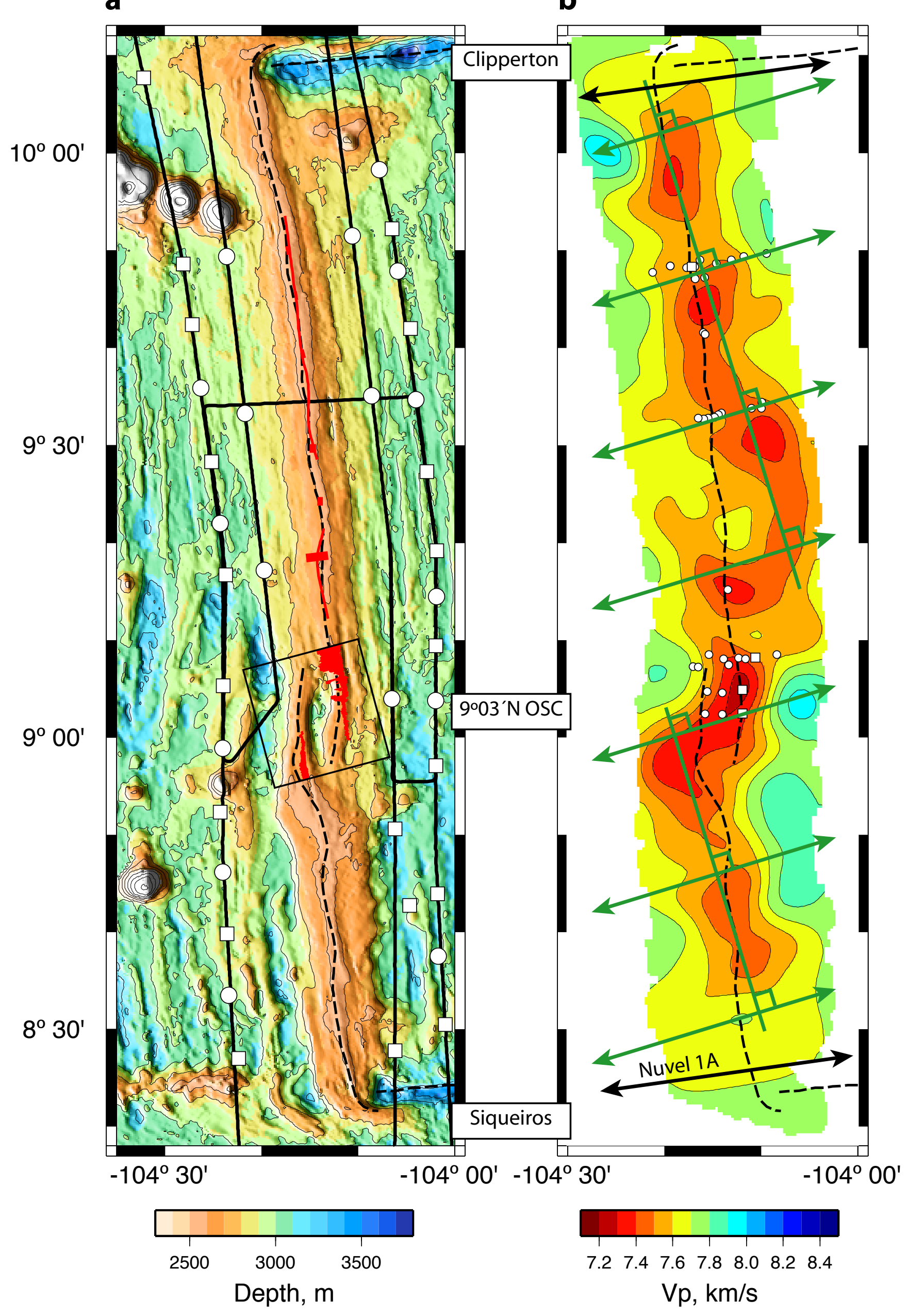

Fig 1 

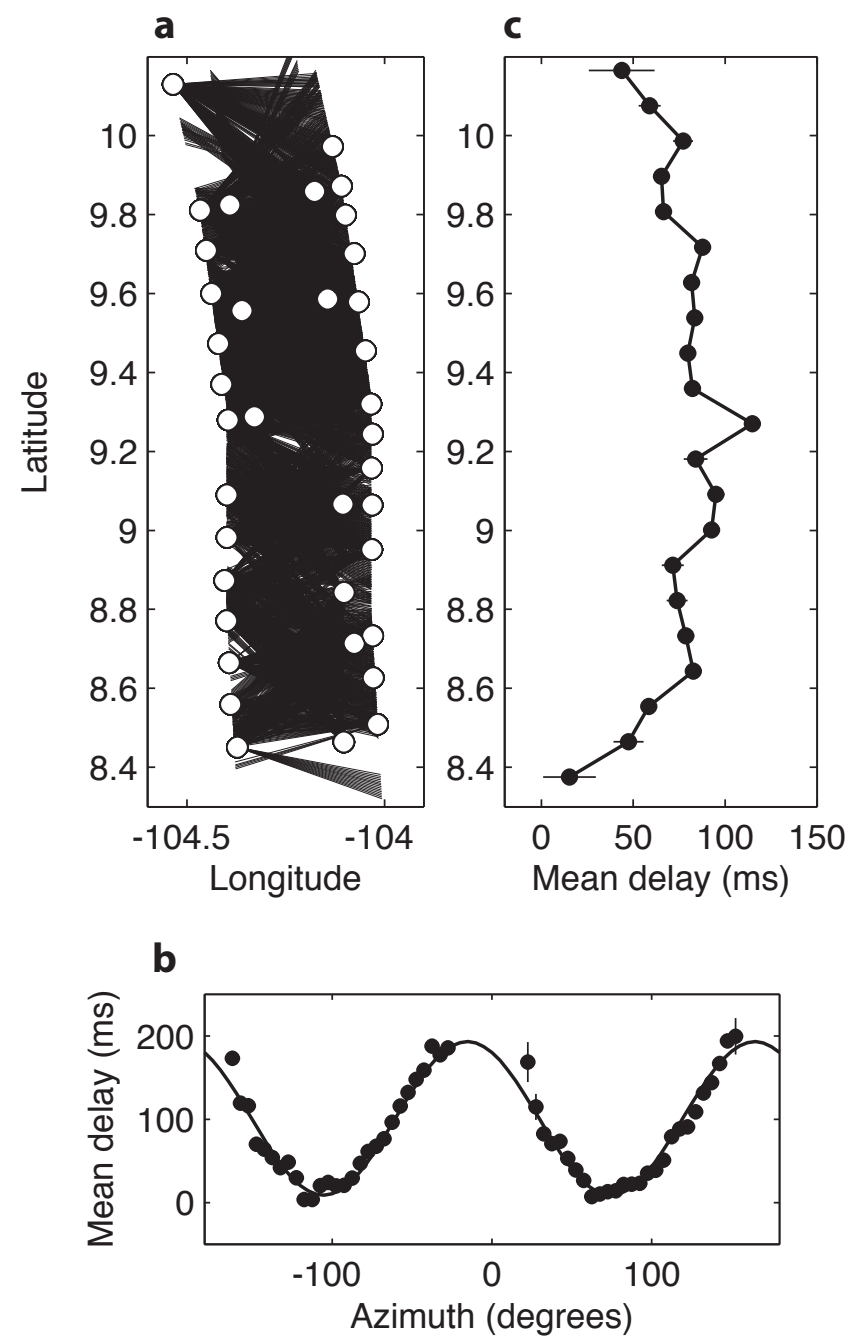

Fig 2 


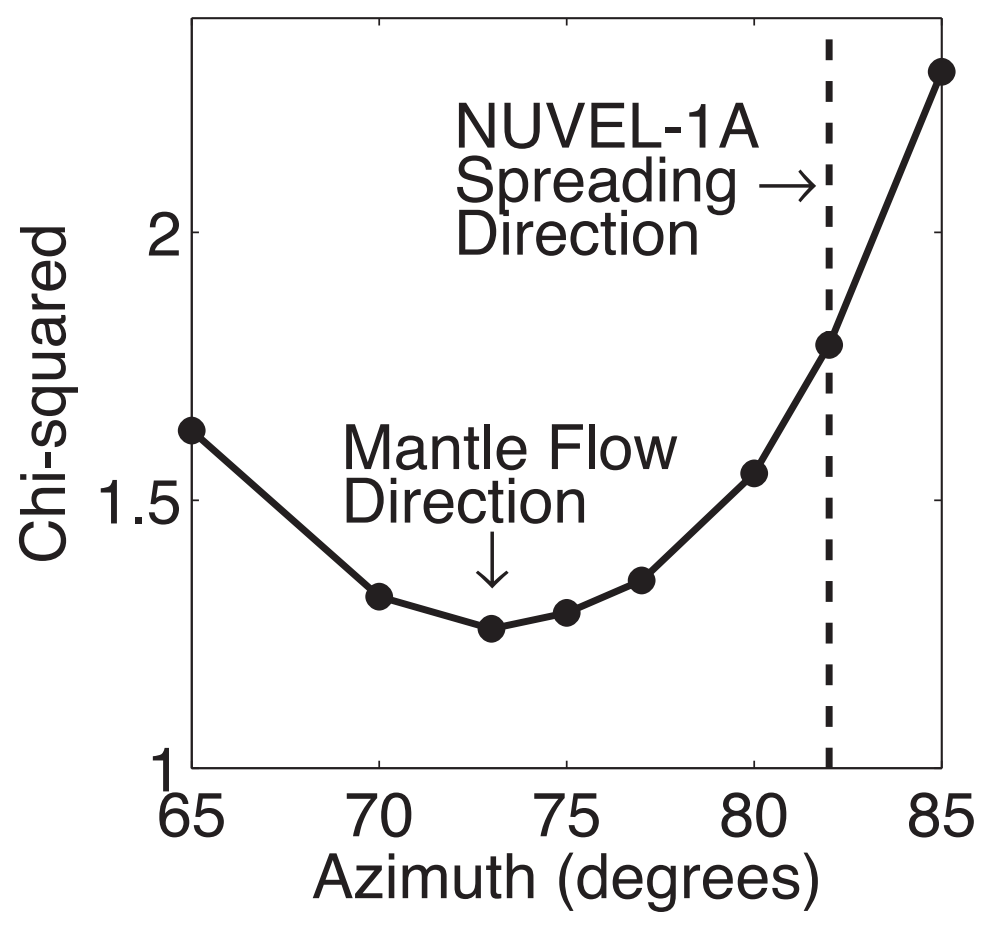

Fig 3 


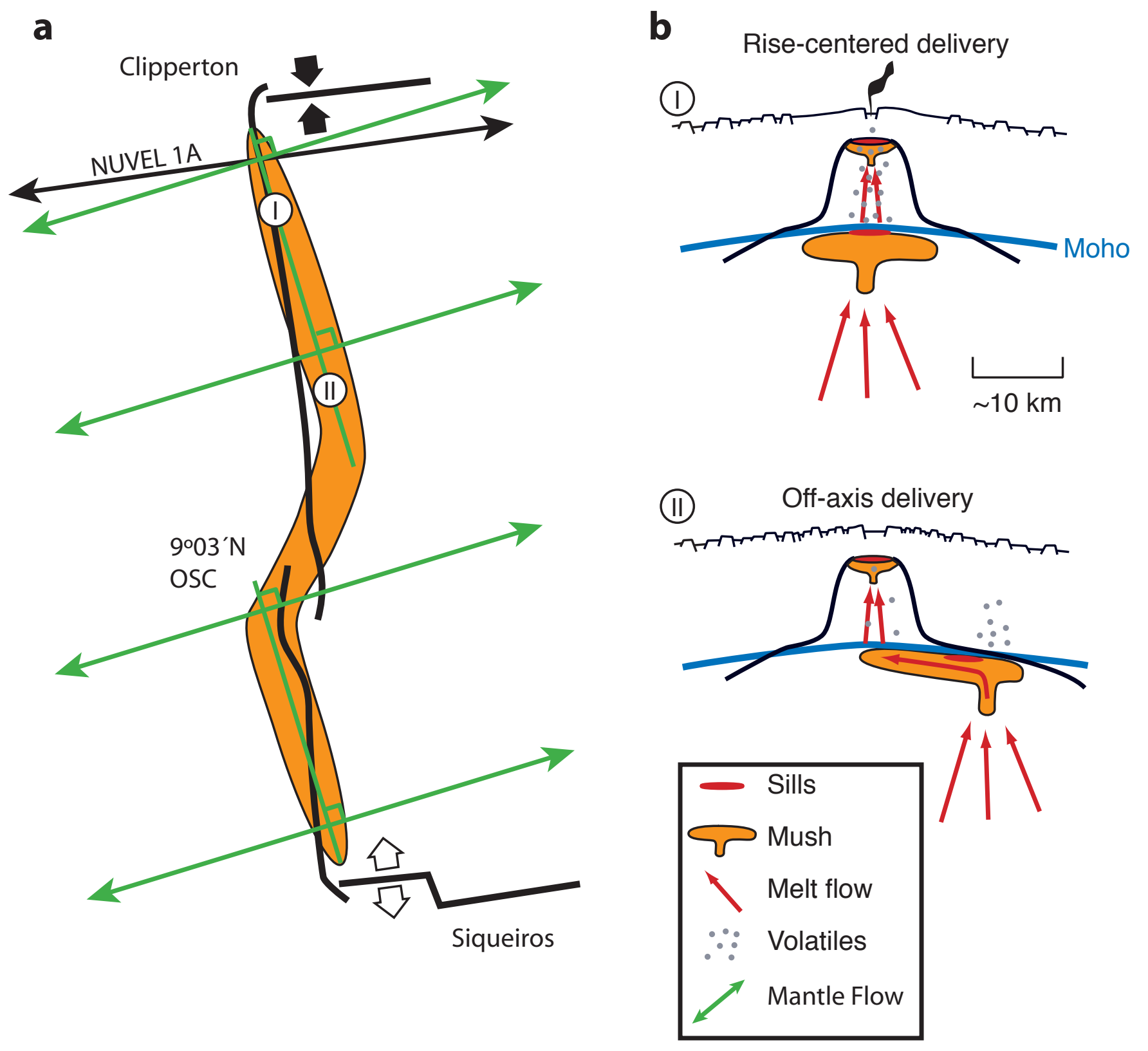

Fig 4 